\title{
Development and application status of multi energy complementary energy system
}

\author{
Yajing Wang ${ }^{1 *}$, Zhuangzhuang Qu ${ }^{1}$, Zhimei Wen ${ }^{1}$ \\ ${ }^{1}$ Shandong Huayu university of technology, Scholl of Energy and Construction Engineering, Dezhou City, Shandong \\ Province
}

\begin{abstract}
With the emergence of energy shortage and environmental problems, multi energy complementary has been widely used. This paper first analyzes the current grim energy situation, and points out the necessity of implementing multi energy complementary. Secondly, it introduces the multi energy complementary power generation system and multi energy complementary heating system, gives several common system forms, and introduces the system composition and process. Finally, the development prospect of multi energy complementary system is analyzed and summarized.
\end{abstract}

\section{Introduction}

Human development cannot be separated from energy. Energy is an essential material basis for economic development and social life, moreover, it is related to the sustainability of society. At present, fossil energy, nuclear energy, wind energy, light energy, heat energy, and natural gas are the main forms of energy utilization, of which fossil energy accounts for the largest proportion.As a big country with large energy consumption, China has a serious shortage of energy resources. In order to achieve sustainable development and alleviate the shortage of fossil energy, China's energy utilization presents the development momentum of "from single energy to multi energy complementary". Multi energy complementary is a new form of energy utilization. According to different energy conditions and energy users, a variety of energy can be used to supplement each other to alleviate the contradiction between energy supply and demand. It can realize the rational use of energy through the rational allocation of energy [1]. In addition, the multi energy complementary comprehensive energy model has realistic environmental benefits and plays a positive role in changing the current worsening environmental problems. Literature [2] points out that the use of multi energy complementary system can reduce the emissions of polluting gases, such as sulfur dioxide and carbon monoxide, and also reduce the emissions of carbon dioxide, contributing to solving global warming. In addition, multi energy complementary can produce huge economic benefits. In addition, the multi energy complementary mode is widely used. Whether in urban or rural areas, multi energy complementary system can be used.

\section{Multi energy complementary power generation system}

Multi energy complementary power generation system multi energy complementary power generation system is the optimal combination of hydropower, wind power, solar power, pumped storage, thermal power and other power sources. It can overcome the shortcomings of single new energy power generation, such as insufficient conversion efficiency, unstable power output and low utilization rate of new energy. With the development of technology, a variety of multi-energy complementary power generation system will be widely used.

\subsection{Wind/ solar complementary system}

With the development of society, wind energy, solar energy and other renewable energy are more and more widely used, which can alleviate the current energy shortage and environmental pollution problems. As a new type of energy, wind energy and solar energy can solve the problem of power supply and improve the power supply system, which plays a positive role in all walks of life and regional economic development. The composition of the system is shown in the Figure 1 [3].

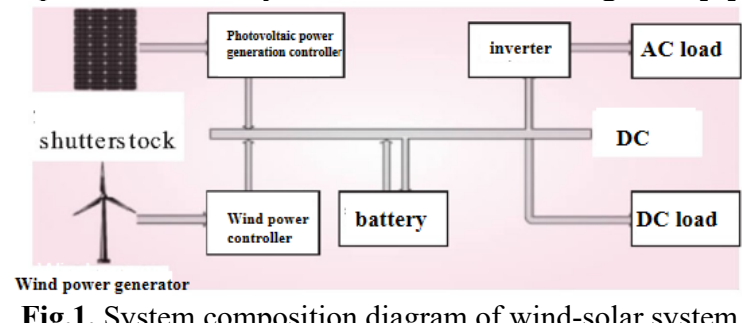

Fig.1. System composition diagram of wind-solar system

$\overline{\text { Crresponding author: wyj@huayu.edu.cn }}$ 


\subsection{Solar/ wind/ ocean complementary system}

This system is based on solar energy, wind energy and ocean energy (wave energy) as a whole [4], mainly including power conversion and power storage after acquiring new energy, as shown in Figure 2 [5].

The multi-energy complementary power generation system has good performance, the whole system ensures the effective conversion of energy, and makes good use of the energy carried by each new energy.

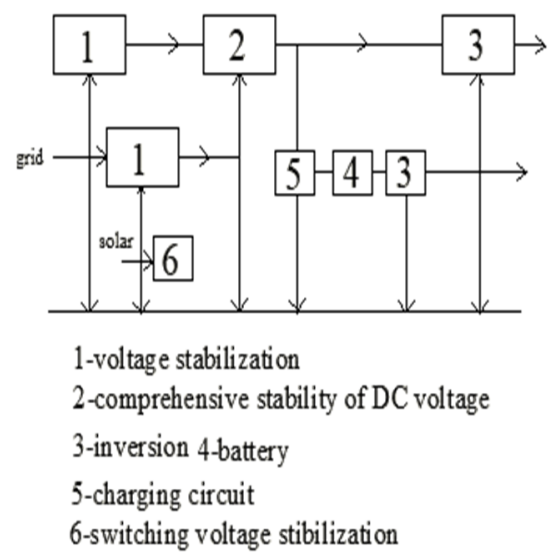

Fig.2. Schematic diagram of solar wind ocean energy system

\subsection{Wind / solar / energy storage complementary system}

The centralized control system of wind solar energy storage multi energy complementary power supply shall be able to realize all the monitoring, control, regulation, diagnosis, analysis and management functions of new energy stations (groups) under its jurisdiction, such as wind farms, photovoltaic, solar thermal, energy storage power stations, etc., as shown in Figure 3 [6].

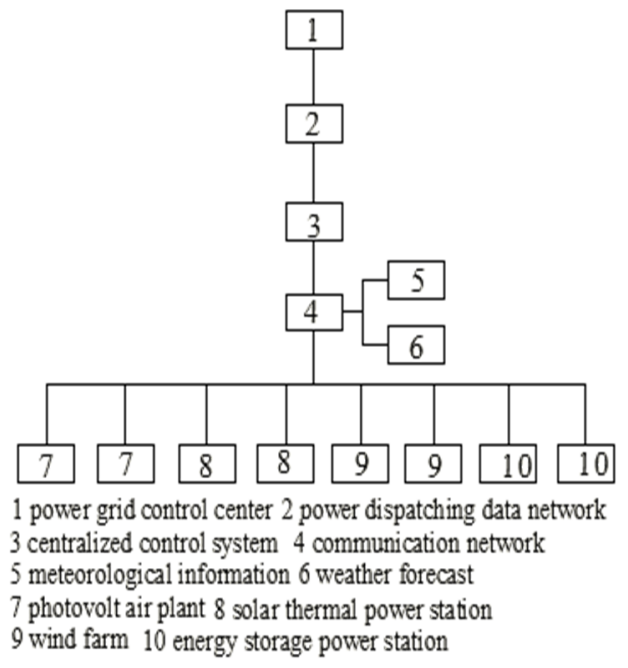

Fig.3. Topography of wind/solar/energy storage complementary system

\subsection{Wind/Solar/Water complementary system}

Based on the physical characteristics of wind, solar, water and other heterogeneous energy and the output characteristics of wind power generation, photovoltaic power generation, hydropower generation system, the system can effectively suppress the fluctuation of wind power generation and photovoltaic power generation output [7].

\section{Multi energy complementary heating system}

In recent years, due to coal-fired heating in winter, haze weather in many areas of China is serious, which poses a great threat to people's health. Multi energy complementary heating system can effectively alleviate the environmental pollution caused by coal-fired heating. Moreover, it can reduce energy waste and promote sustainable development.

\subsection{Solar-heat pump-heat network}

There are two operation modes of complementary heating of expansion valve solar ground source heat pump and heat supply network: one set of ground pipe system and two sets of ground pipe system . It can be seen that the complementary heating system is mainly composed of solar collector system, ground pipe heat exchange system, heat pump unit and heat supply network [8].

\subsection{Solar-air energy system}

As an electric driven renewable energy heating technology, air source heat pump has the advantages of flexible installation and high automation, however its heating performance fluctuates greatly in winter. Therefore, solar energy can be used as an auxiliary heat source in cold weather. The solar-air source heat pump system has the characteristics of high efficiency, energy saving and so on, furthermore, it can improve the stability of the system. Solar air energy heating system is used in some plateau areas. It is the trend of energy application and development to reduce building energy consumption and conventional energy consumption and pollution emissions during the heating period in severe cold areas. Combined with the rational use of regional superior energy, through multi energy complementary "solar energy"+ The comprehensive technology application of "air energy" superior energy can solve the shortcomings of high energy consumption of single application of clean energy in severe cold areas, form a reasonable and applicable multi energy complementary configuration mode, and guide the transition from traditional heating mode to clean heating mode [9]. The system diagram is shown in Figure 4[10,11]. 


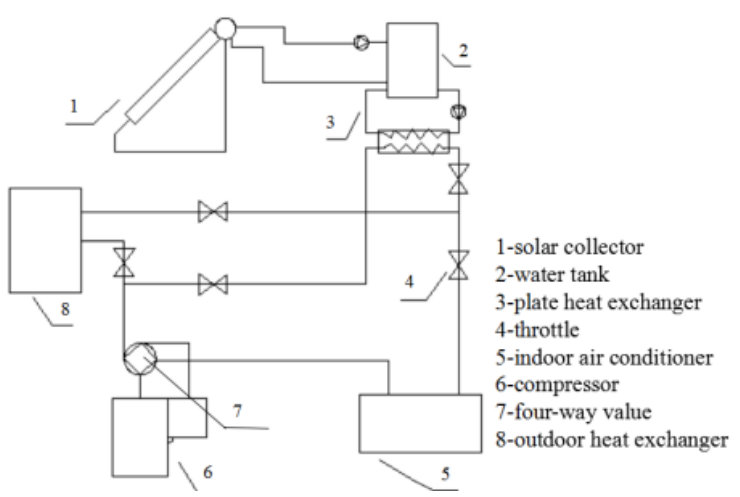

Fig. 4. Solar-air source heat pump heating system.

\subsection{Solar-ground source heat pump heating system}

Solar-ground source heat pump system consists of solar heat collector, water tank regenerator, ground source heat pump, heating distribution equipment, and the pipes to connect the equipment. In the initial period of heating, the outdoor temperature is high and the heating load is small, thus the solar heating system can be firstly and separately used. When the outdoor temperature is low and the heating load is large, the water can be firstly heated by the solar system and then enter into the ground source heat pump for reheating. The flow chart of the system is shown in Figure 5 [12,13].

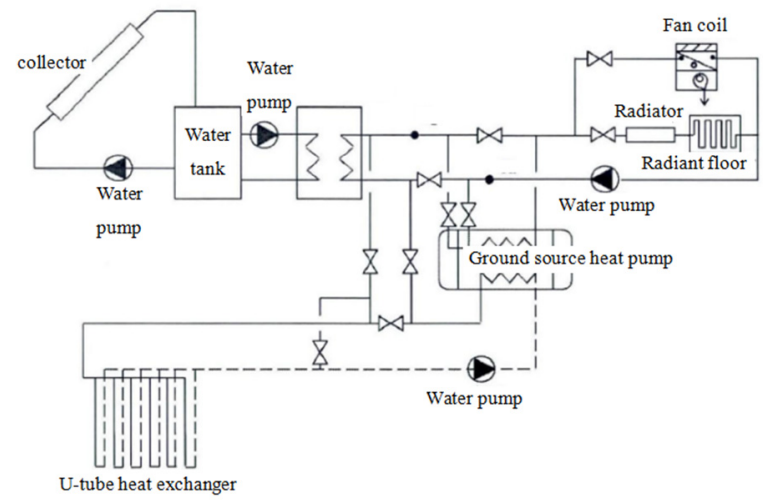

Fig. 5.The flow chart of solar-ground source heat pump heating system.

\section{Prospect and conclusion}

\subsection{Prospect}

As a new form of energy utilization, "Multi-energy complementary" represents the transformation and upgrading of the current energy structure. Under the implementation of "clean coal energy" project, the combination of clean energy and applied technology has promoted the sustainable development of society into a new stage of development.

(1) We should vigorously develop the application of clean energy and reasonably combine solar energy, wind energy and other sources to generate electricity and save fossil energy.
(2) Promote the application of heat pump system: the combination of renewable energy and heat pump system can be used for heating, which greatly improves the system stability.

\subsection{Conclusion}

(1) The development and utilization of "multi energy complementary" energy form solves the problem of single energy discontinuity and ensures the safe and reliable operation of power supply system and heating system.

(2) It solves the environmental problems caused by the use of traditional energy, improves the energy utilization rate to a certain extent, and realizes the sustainable development.

This paper is supported by $R \& D$ center of building energy saving engineering technology of Shandong Huayu University of Technology.

\section{References}

1. Ma, FJ. From single to multi-energy complementary. Heating \& Refrigeration, 10 (2017)

2. Yang, GL. Experimental and Economic Analysis of the Pluripotent Complementary Energy Supply System, Tianjin University. (2012)

3. Zhao YM. Application and optimization design of wind solar hybrid power generation system. Enterprise technology \& development, 10 (2020)

4. Xue CX. Research on control technology of multienergy hybrid isolated power system based on ocean energy. Beijing: National Marine Technology Center.(2014)

5. Xie J, Sang CS, Ma Y, et al. Design of multi-energy complementary power generation system for new energy supply. Journal of Nanjing University of Science and Technology, 44 (2020)

6. Cai LM, He Y, Zhang TJ, et al. Design of Centralized Control System for Wind-light-battery Power Plants. Southern energy constuction, 7 (2020)

7. Yao YX, Ye L, Qu XX, et al. Exergy analysis model of wind-solar-hydro multi-energy generation power system. Electric Power Automation Equipment, 39 (2019)

8. Hao H, Zhi JM, and Yao JB. The Running Mode of the Solar Energy and Ground Source Heat Pump and Heating Network in Cold regions. Journal of Shenyang Jianzhu University (Natural Science), 33 (2017)

9. Liu L, Cao CW. Research on the application of multi energy complementary "solar energy + air energy" heating in Alpine Region. Qinghai science and technology, 27 (2020)

10. Cui XY,. Zhang WJ., Jin H. Performance of solar assisted air-source heat pump in winter. Journal of 
North China Institute of Science and Technology 14 (2017)

11. Dong X, Tian Q, Wu B, Research overview on heating technology of solar-thermal air source heat pump. Journal of Taiyuan University of Technology 48 (2017)

12. Feng J, Zhang XY, Energy saving evaluation method of solar and ground source heat pump coupling system. Constuction Science and Technology, 24 (2011)

13. Huang T, Yuan LH, Wang YH, Optimization design on coupled system with solar energy and ground source heat pump in cold region, Refrigeration and Air-conditioning 12 (2012) 